\title{
ARM RESEARCH IN THE EQUATORIAL WESTERN PACIFIC A DECADE AND COUNTING
}

\author{
by C. N. Long, S. A. McFarlane, A. Del Genio, P. Minnis, T. P. Ackerman, J. Mather,
} J. Comstock, G. G. Mace, M. Jensen, and C. Jakob

\section{A pair of permanent observing sites on the islands of Manus and Nauru have enhanced research into clouds, atmosphere, and radiation in a region where convective systems affect the entire globe}

I thas long been recognized that the tropical western Pacific (TWP) warm pool area acts as the driver of a heat engine that exerts a significant influence on the global climate system. The area is typified by the warmest sea surface temperatures, highest atmospheric water vapor contents, and the greatest coverage of persistent convective cloudiness on Earth, which together result in widespread heavy precipitation and

AfFiliations: Long, McFarlane, Mather, and ComstockPacific Northwest National Laboratory, Richland, Washington; Del GeNIO_NASA Goddard Institute for Space Studies, New York, New York; MINNIs-NASA Langley Research Center, Hampton, Virginia; ACKERMAN—JISAO, University of Washington, Seattle, Washington; MACE-University of Utah, Salt Lake City, Utah; JENSEN-Brookhaven National Laboratory, Upton, New York; JАКОB-Monash University, Melbourne, Australia CORRESPONDING AUTHOR: Dr. Charles N. Long, Pacific Northwest National Laboratory, P.O. Box 999, MSIN: K4-28, Richland, WA 99352

E-mail: chuck.long@pnl.gov

The abstract for this article can be found in this issue, following the table of contents.

DOI:10.1175/BAMS-D-II-00137.I

In final form 15 August 2012

(O2013 American Meteorological Society regions of cirrus overcast. The major scientific interest in the TWP was recognized in the initial planning of the U.S. Department of Energy (DOE) Atmospheric Radiation Measurement Program (ARM; Stokes and Schwartz 1994; Ackerman and Stokes 2003) and prompted the planning for several long-term measurement sites in the TWP area (Ackerman et al. 1999). Because of the lack of long-term scientific-quality surface measurements available in this remote and logistically challenging region, the initial ARM Science Plan (DOE 1996) identified several basic scientific issues relevant to the TWP, which led to the science goals of the TWP component of the ARM Program (Ackerman et al. 1999), as follows:

1) Determining the magnitude of the surface radiation budget terms and their spatial and temporal variability.

2) Identifying bulk and optical properties of clouds in the TWP and how these properties affect the radiation budget.

3) Understanding the linkages among sea surface temperature, ocean-atmosphere coupling, surface radiation budget, and tropical convection.

4) Determining vertical transports of water vapor, energy, and momentum in convective cloud systems. 
The first ARM TWP site was established on Manus Island $\left(2.1^{\circ} \mathrm{S}, 147.4^{\circ} \mathrm{E}\right.$; Fig. 1) in Papua New Guinea with observations starting in October 1996 (Mather et al. 1998). Deep within the warm pool, Manus experiences persistent cloudiness and convective activity, and is influenced by the Madden-Julian oscillation (MJO; Madden and Julian 1994; Zhang 2005). The second equatorial ARM TWP site was established on the western side of the tiny island nation of Nauru, at $0.5^{\circ} \mathrm{S}, 166.9^{\circ} \mathrm{E}$, in November 1998 . Nauru sits on the eastern edge of the warm pool and experiences strong variability associated with ENSO. Manus and Nauru provide the longest set of concurrent ground-based measurements of cloud and radiation properties available in the tropical western Pacific outside of Australia. A third nonequatorial site was established at the Australian Bureau of Meteorology facility in Darwin, Australia, during March 2002. The Darwin site is an important example of a tropical land site and exhibits strong seasonal variability associated with the Australian summer monsoon; however, because it is not representative of the tropical ocean, we do not discuss it further in this article.

The early years of the ARM deployments in the remote locations of the TWP provided many challenges. The ground-breaking idea of continuously operating modern active remote sensing instrumentation (such as lidars and cloud radars), which forms the basis of the ARM measurement paradigm, provided serious logistical challenges, resulting in some significant data gaps in the early years for some of the active sensors. These early

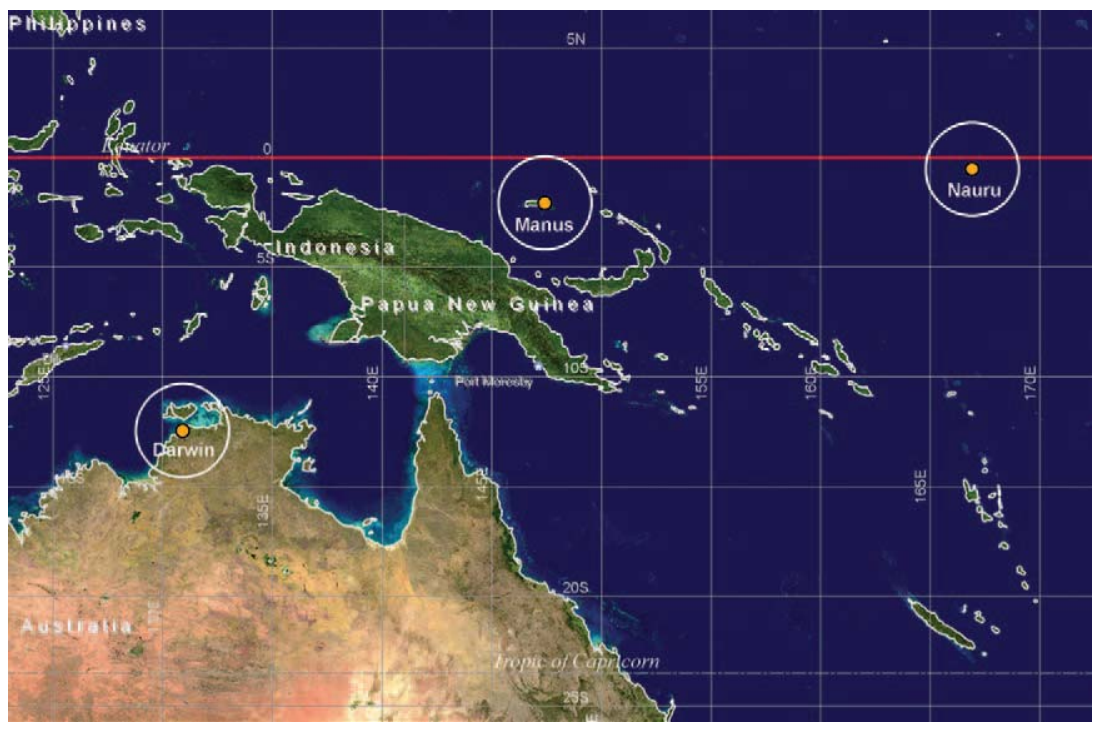

FIG. I. Atmospheric Radiation Measurement (ARM) Tropical Western Pacific (TWP) sites. Image courtesy of the U.S. Department of Energy ARM Climate Research Facility. difficulties have since been overcome, resulting in substantially more continuous and reliable datasets. The more traditional observational systems (e.g., surface radiative fluxes and meteorology) have performed well since their deployment.

Although the TWP ARM sites are single locations in a large region, there is evidence that they are representative of the larger tropics. Using two years of geostationary satellite data across the TWP, Jakob et al. (2005) used $k$-means clustering to define four tropical cloud regimes and found that all of the regimes existed at the Manus site, indicating that the Manus observations are representative of the larger TWP region. This is of great significance because it implies that findings relying on long-term measurements at the ARM TWP sites can likely be extrapolated to other TWP locations.

Over a decade of ARM measurements has resulted in a unique long-term observational dataset that has been widely used to extend our understanding of the TWP climate regime as well as tropical clouds and convection in general. The goal of this article is to highlight the utility of the TWP dataset by presenting some examples of its use in a diverse range of scientific investigations.

\section{TROPICAL RADIATION BUDGET, CLOUD PROPERTIES, AND CLOUD RADIATIVE}

IMPACTS. Absorbed solar energy in the tropics is redistributed through longwave radiative exchange, the hydrologic cycle, and dynamical transport. Clouds significantly impact the radiative exchange and the condensation and are, in turn, affected by interannual and intraseasonal variability. The comprehensive ARM measurements provide a unique capability to study the radiation budget in the full context of the thermodynamic and cloud structures affecting it. Figure 2 shows the time series of monthly average downwelling shortwave (SW) and longwave (LW) cloud effects for Manus and Nauru. These calculations use the clear-sky estimation techniques from Long and Ackerman (2000) and Long and Turner (2008) for the SW and LW fluxes, respectively.

Because of the large column water vapor amounts and warm near-surface air 


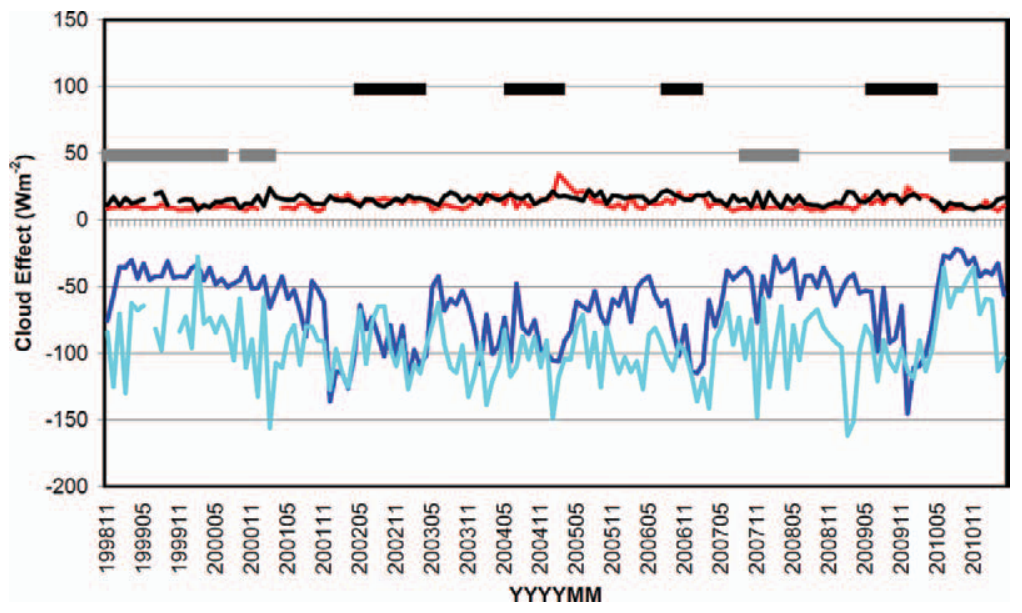

FIG. 2. Monthly averages of daylight downwelling SW cloud effect for Manus (light blue) and Nauru (blue), and 24-h downwelling LW cloud effect (black line for Manus, red for Nauru). La Niña and EI Niño periods are indicated by gray and black bars, respectively, based on the Oceanic Niño Index (ONI) from the National Weather Service (NWS) Climate Prediction Center (CPC).

temperatures associated with the warm pool, the atmosphere is nearly opaque in the infrared. Thus, the downwelling surface LW flux varies little either temporally or spatially (Long 1996), even in the presence of inhomogeneous cloud fields, and has a cloudless sky value of about $400 \mathrm{~W} \mathrm{~m}^{-2}$ for both equatorial TWP sites. The monthly downwelling LW cloud effect for both sites varies little, and is relatively small, averaging only $12 \mathrm{~W} \mathrm{~m}^{-2}$ for Nauru and $15 \mathrm{~W} \mathrm{~m}^{-2}$ for Manus (Fig. 2).

The SW cloud effect exhibits significantly more variability, averaging $-64 \mathrm{~W} \mathrm{~m}^{-2}$ for Nauru and $-95 \mathrm{~W} \mathrm{~m}^{-2}$ for Manus. One of the strongest modes of interannual variability in the TWP is associated with ENSO. Because of persistent cloudiness, the downwelling SW irradiance at the Manus ARM site exhibits virtually no ENSO signal. Nauru, on the other hand, exhibits a strong signal difference between El Niño and La Niña conditions, with increased SW cloud effects during El Niño when the main areas of deep convection and its associated cloud fields shift toward the central Pacific. Figure 3 depicts the relative frequency of occurrence of daylight cloud amounts retrieved using the Long et al. (2006) technique separated into El Niño and La Niña periods for Nauru and Manus. The minimal difference between the two regimes at Manus, showing only a slightly greater occurrence of nearly clear skies during La Niña, contrasts with the strikingly different distributions between the two regimes at Nauru. For El Niño conditions, the Nauru distribution is very similar to that at Manus. But for La Niña periods, the Nauru distribution shows that cloud fractions of $50 \%$ or less occur most frequently and overcast skies occur much less frequently than during El Niño periods or at Manus.

Another important mode of variability that is well documented in the ARM TWP data (e.g., Chen and Del Genio 2009; Wang et al. 2011) is the Madden-Julian oscillation (Madden and Julian 1994; Zhang 2005). In contrast to ENSO variability, the Manus site, rather than Nauru, exhibits a significant MJO cloud and radiation signal. The Nauru site is located to the east of the primary area of tropical convection and consequently shows little impact of the MJO on cloud occurrence and effect. Wang et al. (2011) use a wavelet power analysis to demonstrate a distinct MJO signal in both cloud amount and downwelling SW cloud effect at Manus (Fig. 4). They also show an MJO influence on the average diurnal cycle of cloudiness; there is increased cloudiness, with corresponding increases in magnitude of the downwelling SW cloud effects, during the early morning and later afternoon during active phases of the MJO.

The TWP ARM datasets are unique in the tropics because of the long-term synergy provided by active (radar and lidar) and passive remote sensors that cover

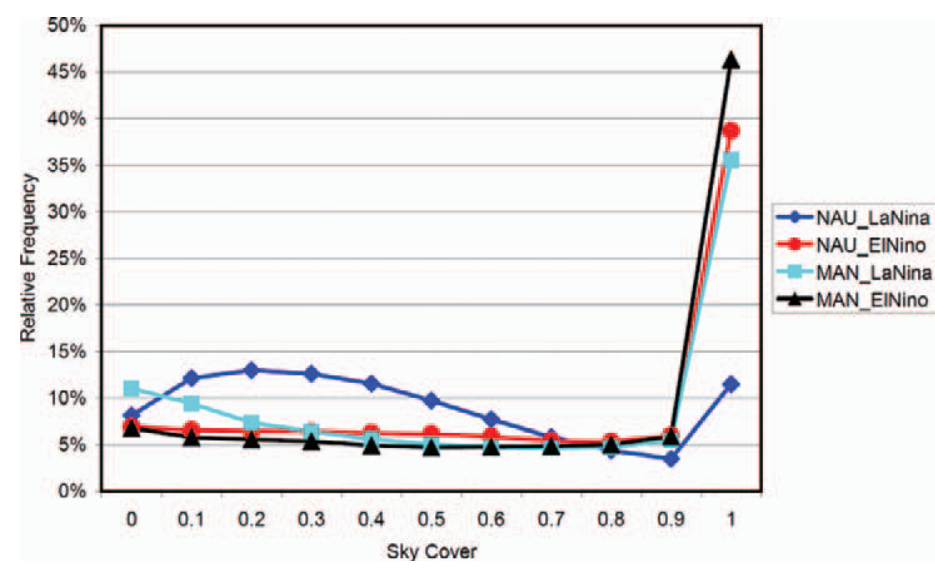

FIG. 3. Relative frequency of occurrence of daylight fractional sky cover for EI Niño (red) and La Niña (blue) conditions at Nauru, and for EI Niño (black) and La Niña (light blue) conditions at Manus. 
the electromagnetic spectrum from the ultraviolet to the microwave combined with frequent radiosonde soundings. The use of vertically pointing millimeterwavelength cloud radar and lidar to derive cloud macrophysical parameters is illustrated in Fig. 5, which shows the composite hydrometeor frequency profile as a function of time of day from Manus (top) and Nauru (bottom). The hourly hydrometeor frequency profiles are calculated as the fraction of time within each hour-long period that the radar reflectivity from the Active Remote Sensing of Clouds (ARSCL) product (Clothiaux et al. 2000) at the given height is larger than $-40 \mathrm{dBZ}$ and has a signal-to-noise ratio greater than $-18 \mathrm{~dB}$. Hours with more than $25 \%$ bad or missing data are not included in the composite.
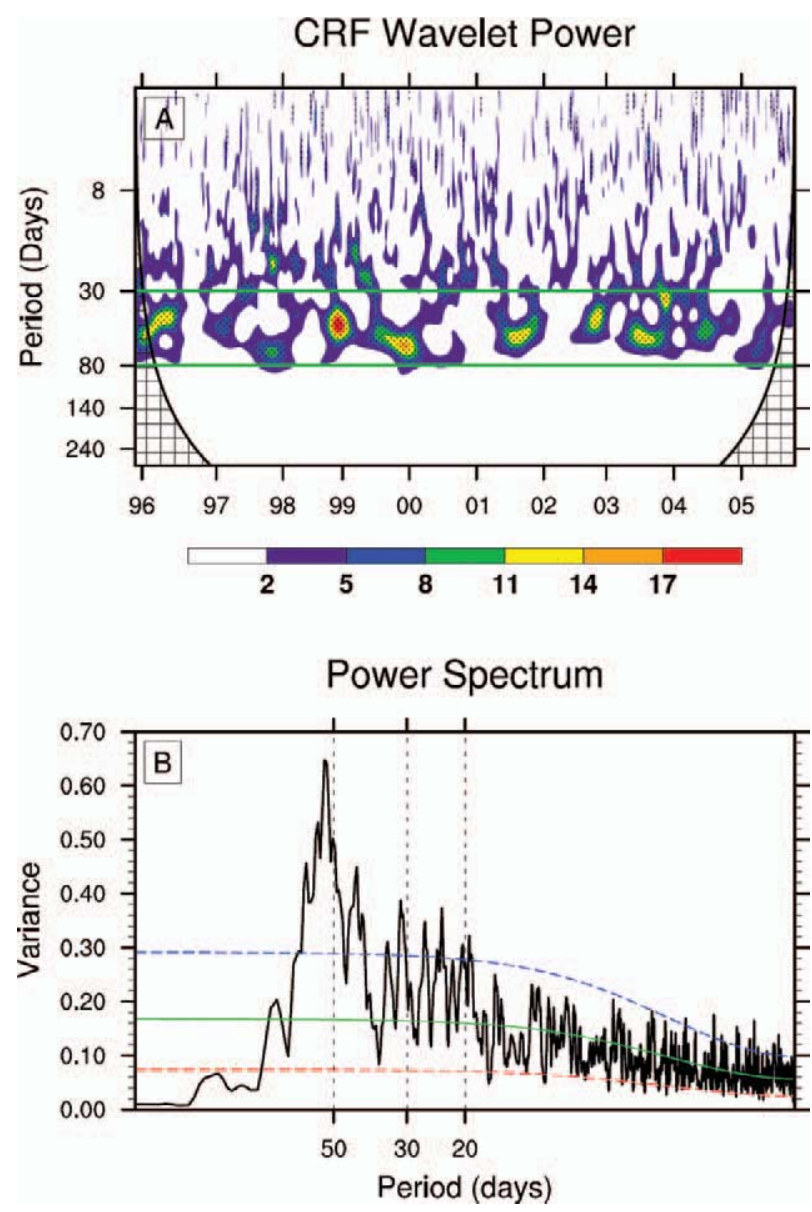

FIG. 4. (a) Wavelet power of SW downwelling cloud effect (color shading) with two green lines that indicate the 30- and 80-day periodicity for Manus. Crosshatched regions on either end indicate the area in which the edge effect becomes important. Areas of statistically significant wavelet power are stippled. (b) The Fourier power spectrum of the SW cloud effects with overlaid best-fit red noise spectrum (green) and a $95 \%$ confidence envelope (dashed lines, red and blue). Adapted from Wang et al. (20II).
The Manus data exhibit a strong diurnal cycle, with a maximum in low cloud frequency occurring just after local noon and a maximum in high cloud frequency occurring several hours later. Nauru has a much weaker composite diurnal cycle, although there is a maximum in low cloud around local noon. Midlevel hydrometeors occur substantially more often at Manus than Nauru, associated with the more frequent convection at Manus, which leads to detrainment at and just above the $0^{\circ} \mathrm{C}$ freezing level. The strong diurnal cycle at Manus is likely related to its proximity to the Maritime Continent, including the large island of New Guinea, approximately $300 \mathrm{~km}$ to the south. Mather (2005) shows a strong correlation between high cloud occurrence over Manus and outgoing longwave radiation (OLR) over New Guinea. Since models generally have difficulty reproducing the diurnal cycle of convection within the Maritime Continent region (Neale and Slingo 2003), the Manus data are a source of comparison with some relevance.

Cloud-base and cloud-top heights deduced from the radar and lidar data are used to define cloud type, which can then be combined with the cloud radiative effect derived from the broadband radiometers to examine the radiative effects of different cloud (Fig. 6). The data indicate clear differences among the frequency distributions of
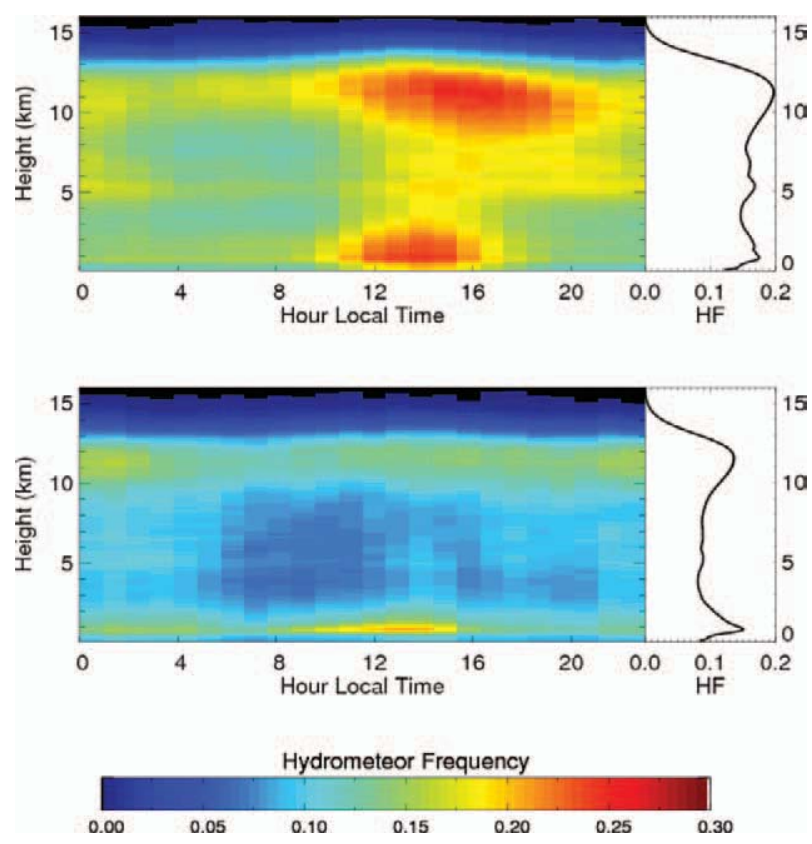

FIG. 5. The composite radar hydrometeor frequency (HF) (left) as a function of time of day and (right) the daily mean value from all available data at (top) Manus and (bottom) Nauru. 
SW transmissivity segregated by cloud type. Not surprisingly, deep convective clouds have the lowest transmissivity, while cirrus have the highest transmissivity. Low clouds have the broadest distribution of SW transmissivity due to variations in both cloud thickness and cloud fraction. Although the frequency of the various cloud types differs at the two sites, the radiative characteristics of each cloud type are similar for the two sites. Categorized statistical distributions such as these provide fruitful comparisons with similar distributions obtained from climate models.

Concurrent deployment of multiple active and passive sensors at the ARM TWP provides an opportunity to probe the microphysical properties of tropical clouds. For example, using knowledge about hydrometeor scattering properties and fall velocities obtained from laboratory studies and aircraft measurements, the backscatter and Doppler velocity from the radar and lidar measurements can be inverted to retrieve vertically resolved profiles of ice and liquid water content and particle size (Comstock et al. 2002; McFarlane et al. 2002; Mather et al. 2007; Deng and Mace 2008).

Long-term datasets on vertically resolved cloud macro- and microphysical properties enable a wide range of studies of tropical cloud radiative impacts and processes. For example, vertical profiles of cloud microphysical properties combined with information on the atmospheric temperature and humidity structure from soundings have been used as inputs to a radiative transfer model in order to calculate the cloud radiative effect (McFarlane and Evans 2004; Comstock et al. 2002) and the vertical profile of radiative heating due to tropical clouds (Mather et al. 2007; Fueglistaler and Fu 2006). Although the average net radiative effect of tropical cloud systems at the top of the atmosphere (TOA) is small due to the compensating effects of heating and cooling across an ensemble of cloud types (Hartmann et al. 2001), ARM observations show that tropical clouds act to redistribute energy in the atmospheric column (McFarlane et al. 2007), which may impact both cloud-scale and larger-scale dynamics. High tropical cirrus also impact the radiative heating in the lower stratosphere, which may be important to stratospheric mixing and moisture transport (Fueglistaler and Fu 2006; Dinh et al. 2012).

The ARM radar/lidar measurements have been used extensively in studies of the tropical convective lifecycle, taking advantage of both the continuous nature and high temporal resolution of the measurements to investigate long-term statistics of cloud processes. Kollias and Albrecht (2010) derived
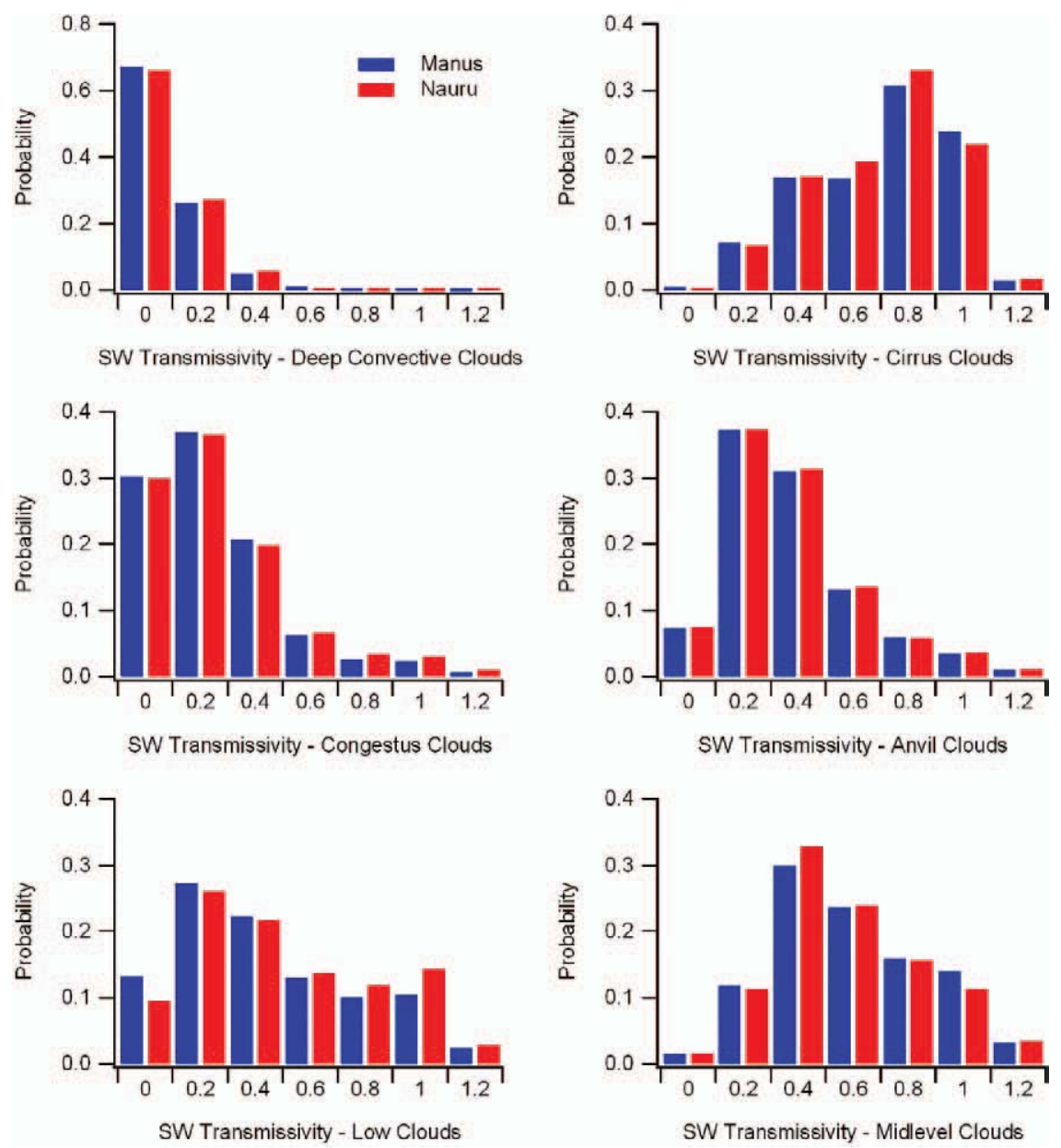

FIG. 6. Histogram of SW transmissivity measured by broadband radiometers as a function of cloud type at Manus (blue) and Nauru (red). Cloud types are identified using cloud-base and cloud-top heights from radar measurements. Low clouds, congestus, and deep convection all have cloud bases $<4 \mathrm{~km}$ with tops $<4 \mathrm{~km},<8 \mathrm{~km}$, and $>8 \mathrm{~km}$, respectively. Midlevel clouds have bases between 4 and $8 \mathrm{~km}$. Cirrus and anvil have bases $>8 \mathrm{~km}$ but the former are less than $1.5 \mathrm{~km}$ thick, while the latter are greater than $1.5 \mathrm{~km}$ thick. 
statistical distributions of in-cloud vertical velocity from multiple years of radar data at Nauru. They examined the statistics of land-forced and oceanforced shallow cumuli separately and found distinct differences that can be used to test shallow cumulus mass flux and turbulence parameterizations in models. Many models are not able to accurately simulate the timing of the transition from shallow to deep convection. Jensen and Del Genio (2006) combined radar measurements with sounding observations at Nauru to show that the existence of dry layers in the midtroposphere is more important than freezing-level stability for inhibiting the growth of congestus clouds into deep convection. Mace et al. (2006) used ARM radar observations to examine relationships between cirrus microphysical properties and convection. They found that cirrus microphysical properties vary systematically with time since convective origin. Younger anvil cirrus have a bimodal distribution of radar reflectivity and a broad probability distribution function (PDF) of Doppler velocity, indicating a range of particle sizes. As the anvil ages, the large reflectivity mode decays, likely due to sedimentation of large particles, and the PDF of velocity narrows. Mace et al. (2006) also found that less than half of the cirrus observed at the ARM sites could be directly traced to convective systems, indicating that other dynamical processes are acting to produce and maintain tropical cirrus. These types of studies provide significant insights into tropical cloud processes that can be further explored using cloud and climate models.

MODEL EVALUATION AND DEVELOP. MENT. The long time series of ARM data on cloud and environmental vertical structure at Manus and Nauru provide an excellent resource for testing of cloud parameterizations used in general circulation models (GCMs) and finer-scale models, as well as insights into physical process deficiencies that can lead to model improvement. Consequently, many process model, GCM, and single-column model (SCM) studies have made use of ARM TWP data. Since ARM data provide instantaneous information at a spatial scale much smaller than a GCM grid box, model evaluation over short time scales can only be conducted using a probabilistic approach (Jakob et al. 2004). To date, most model evaluations have opted instead to examine longer-term statistics of cloud and environmental fields in one of two ways. The studies either use runs from a free-standing model, which exposes the model's actual climate including feedbacks between the clouds and general circulation, or conduct a large series of short-term forecasts in a model initialized with a numerical weather prediction (NWP) analysis product, which seeks to isolate recurring parameterization errors by calculating the model's response to an assumed realistic atmospheric state.

Ovtchinnikov et al. (2006), for instance, show that a multiscale modeling framework (MMF) climate model simulates clouds at the ARM Nauru site with statistics that are much closer to measurements than does the conventional Community Atmosphere Model (CAM). On the other hand, the MMF version was not superior to the standard CAM at the ARM Southern Great Plains (SGP) site. Boyle et al. (2005) use the short-term forecast approach to show that the CAM consistently underpredicts low and midlevel cloudiness relative to the Active Remote Sensing of Clouds product (Clothiaux et al. 2000) and slightly overpredicts high cloud at Manus and Nauru as well as the SGP, suggesting an overly vigorous cumulus parameterization. A potential limitation of initializing models with NWP analysis products is that, for the tropics, few soundings are available for assimilation and the strong quasigeostrophic constraint is weak. Thus, the analysis itself may incur significant errors due to its reliance on underlying model parameterizations rather than on observations. Hume and Jakob $(2005,2007)$ proposed a novel solution to this problem, developing an ensemble SCM forcing technique that uses multiple analysis products. They show that this approach can potentially separate model errors due to model sensitivity to forcing errors from those truly brought about by parameterization errors.

McFarlane et al. (2007) derive vertical profiles of radiative heating rate at Nauru and Manus from ARM data and compare them to heating rates from free-standing simulations using the conventional and MMF versions of CAM 3.0 (Fig. 7). Their results show that both models have more tropical high cloudiness than the surface-based observations. Clouds both absorb and emit longwave radiation, and hence whether a given layer is heated or cooled due to the presence of clouds depends on the contrast between the radiating temperature of the cloud and the surrounding atmosphere. These compensating effects then often produce a small net longwave heating rate. When the average profiles of longwave heating (Fig. 7a) and cooling (Fig. 7b) by clouds are examined separately, the data and models show regions of both longwave heating and cooling but the peak longwave cooling due to ice clouds in the ARM dataset occurs $\sim 2 \mathrm{~km}$ lower than in the models. The standard CAM produces considerably more optically thin, very high cirrus, which then create significant net heating near the tropopause 
that is not captured in the observations. However, it is possible that the surface observations may undersample the high, thin cirrus due to instrument sensitivity limitations. Chen and Del Genio (2009) compare ARSCL cloud-top height distributions at Manus and Nauru to analogous profiles from International Satellite Cloud Climatology Project (ISCCP) and the Goddard Institute for Space Studies (GISS) GCM, aggregated by weather states defined by a $k$-means clustering algorithm. Their approach demonstrates a bias in ISCCP cloud-top heights and confirms the dearth of middle-top clouds in the GCM, similar to the conclusions of Boyle et al. (2005) for the CAM.

Other TWP modeling studies employing the ARM datasets have produced fundamental insights into particular aspects of cloud behavior important for GCM parameterizations. Comstock and Jakob (2004) compare simulated cirrus clouds in the European Centre for Medium-Range Weather Forecasts (ECMWF) model against ARSCL data at Nauru. They find that about half the observed cirrus are directly associated not with convective events but rather with large-scale uplift and cooling; the model exhibits a similar partitioning. On the other hand, millimeter radar time series of neartropopause cirrus evolution show that the layers tend to descend with time, suggesting significant sedimentation rates for cloud ice particles in these clouds. The ECMWF model, which at the time did not account for cloud ice fallout, simulates constant cirrus altitudes instead. Zhu and Bretherton (2004) evaluate a new shallow cumulus parameterization in a regional model for both a tropical maritime environment (Nauru) and a midlatitude continental environment (SGP) against ARM measurements. At the SGP shallow cumulus are dominated by buoyant convection, while at Nauru they are dominated by forced convection whose only buoyancy production is in the subcloud layer. The original version of the cumulus scheme accounted only for buoyant shallow cumulus (as do most other models), but by redefining the convective inhibition to only account for negative buoyancy below the lifting condensation level, they were able to simulate both types of convection with the new parameterization.

Although clouds and radiation have been priorities for ARM TWP science, routine soundings and surface meteorological observations, both of which are rare in this region, provide unique insights into the thermodynamic state of the tropical atmosphere. Romps and Kuang (2011), for example, show that most convective parcels at Nauru originate in the lowest $100 \mathrm{~m}$ of the atmosphere; this has implications for GCM estimates of convective available potential energy (CAPE) and the design of entrainment parameterizations. Using sounding data at Nauru, Holloway and Neelin (2009) show that the previously documented systematic increase of vertically integrated humidity as precipitation increases (Bretherton et al. 2004) is dominated by changes in the free troposphere rather than the boundary layer. This type of diagnostic is a useful indicator of a realistic GCM MJO simulation and has direct implications for the parameterization of convective entrainment and rain evaporation (Zhu et al. 2009; Thayer-Calder and Randall 2009; Kim et al. 2009; Hannah and Maloney 2011; Del Genio et al. 2012).

SATELLITE COMPARISON AND VALIDATION. While satellite validation was not an original stated goal of ARM, the decade-long record of unique measurements collected at the equatorial Manus and 


\section{WHAT OBSERVATIONS ARE AVAILABLE AND HOW TO GET THEM}

The ARM Program maintains a website (www.arm .gov) where a wealth of information is available about the program, the sites, instrumentation, and contact information. A sister site for the Atmospheric System Research (ASR) Program (asr.science.energy.gov) gives information about the science program that is specifically devoted to using ARM data. The website www.arm.gov/sites/twp gives information about the TWP sites in particular, including links to the specific instrumentation of each site; from there, links can be followed for each instrument listed to "build an order" for data. Alternately, the ARM Archive website at www.archive.arm.gov provides several ways to access data files and build data orders, view plots, and link to data quality assessment reports and graphics. All ARM data are available to anyone free of charge. Additionally, each order for ARM data is accompanied by a summary listing of relevant ARM Data Quality Reports (DQRs) describing all known issues with the data, including the relevant time periods, with links to the on line full-detail reports.

Table I lists the instruments and instrument systems operating at the TWP sites, along with a brief description of what physical quantity is measured by each. Many instruments such as cloud radars, lidars, microwave radiometers, radiosondes, and surface radiation instruments have been operated since the inception of each site. Some instruments have recently been upgraded (marked with a single asterisk) or are newly added (marked with two asterisks) with the benefit of Recovery Act funding. We note that the Millimeter Wavelength Cloud Radar (MMCR), Micropulse Lidar (MPL), and Atmospheric Emitted Radiance

\begin{tabular}{|c|c|c|}
\hline Abbrev. & Name & Description \\
\hline SKYRAD & Sky Radiometers for Downwelling Radiation & Downwelling broadband SW and LW irradiances \\
\hline GNDRAD & Ground Radiometers for Upwelling Radiation & Upwelling broadband SW and LW irradiances \\
\hline IRT & Infrared Thermometer & Sky brightness temperature \\
\hline MFRSR & Multifilter Rotating Shadowband Radiometer & $\begin{array}{l}\text { Spectral total, direct, and diffuse irradiance in } 8 \mathrm{SW} \\
\text { channels }\end{array}$ \\
\hline CSPHOT & Cimel Sunphotometer & Spectral direct radiance in 6 channels \\
\hline SMET & Surface Meteorological Instruments for TWP & $\begin{array}{l}\text { Standard height air temperature, pressure, humidity, wind } \\
\text { speed and direction }\end{array}$ \\
\hline MET** & Surface Meteorological Instrumentation & $\begin{array}{l}\text { Standard height air temperature, pressure, humidity, wind } \\
\text { speed and direction }\end{array}$ \\
\hline RAIN** & Rain Gauge & Rainfall amounts \\
\hline SONDE* & Balloon-Borne Sounding System & $\begin{array}{l}\text { Vertical profiles of temperature, humidity, pressure, wind } \\
\text { speed and direction }\end{array}$ \\
\hline MWR & Microwave Radiometer & Column integrated water vapor and liquid water amounts \\
\hline $\mathrm{AERI} * *$ & Atmospheric Emitted Radiance Interferometer & $\begin{array}{l}\text { High resolution absolute infrared spectral radiance over } \\
3-19.2-\mu \mathrm{m} \text { range }\end{array}$ \\
\hline TSI & Total Sky Imager & $\begin{array}{l}\text { Daylight hemispheric sky images, sky cover retrievals, and } \\
\text { daily sky movies }\end{array}$ \\
\hline VCEIL* & Vaisala Ceilometer & $\begin{array}{l}\text { Cloud-base height at up to three levels, potential } \\
\text { backscatter by aerosols. }\end{array}$ \\
\hline MPL* & Micropulse Lidar & 523-nm wavelenqth backscatter signals up to $20+\mathrm{km}$. \\
\hline MMCR & Millimeter Wavelength Cloud Radar & $35-\mathrm{GHz}$ radar reflectivity $(\mathrm{dBZ})$ profiles up to $20 \mathrm{~km}$ \\
\hline KAZR** & Ka-Band ARM Zenith Radar & $\begin{array}{l}36-\mathrm{GHz} \text { radar reflectivity, vertical velocity, and spectral } \\
\text { width profiles up to } 20 \mathrm{~km}\end{array}$ \\
\hline KASACR* & Ka-Band Scanning ARM Cloud Radar & Ka-band dual-frequency, dual-polarization Doppler radar \\
\hline XSACR** & X-Band Scanning ARM Cloud Radar & X-band dual-frequency, dual-polarization Doppler radar \\
\hline CSAPR ** & C-Band ARM Precipitation Radar & C-band dual-polarization Doppler weather radar \\
\hline
\end{tabular}


Interferometer (AERI) were removed from Nauru in mid-February of 2009, largely due to programmatic budget constraints at the time. However, all other instruments continue operations at the Nauru site.

The ARM Program produces Value Added Products (VAPs) that enhance the utility of observations through more extensive data quality control, and enhanced processing. In some cases, the VAPs also combine observations from multiple instruments and/or observations and models to produce atmospheric quantities that cannot be derived using a single set of observations. Table 2 lists some of the more popular examples of TWP VAPs. A large number of VAP systems have been operational for many years, steadily producing results in an automated processing mode. Others listed as "Evaluation Products" are preliminary products provided to the community for evaluation and comment regarding their content and usefulness before being finalized for automated production as programmatic VAPs. "External VAPs" are similar to the ARM operational products but are produced by organizations external to the ARM Program. Finally, other VAPs that are produced by individual ARM/ASR Principal Investigators (PIs) and deemed useful to the broader community are hosted and made available as "PI Products" through the ARM Archive. Information on all of the TWP VAPs is available at www.arm.gov/data/vaps.

\begin{tabular}{|c|c|c|}
\hline Abbrev. & Name & Description \\
\hline AERINF & AERI Noise Filtered & $\begin{array}{l}\text { Process to reduce the uncorrelated random error using } \\
\text { principal component analysis (PCA). }\end{array}$ \\
\hline AOD & Aerosol Optical Depth & Retrieved aerosol optical depths from MFRSR data. \\
\hline ARSCL & Active Remotely-Sensed Cloud Locations & $\begin{array}{l}\text { Combines data from cloud radar, MPL, and VCeil to } \\
\text { produce vertical profile of cloud boundaries, estimates } \\
\text { of radar reflectivities, vertical velocities, and Doppler } \\
\text { spectral widths. }\end{array}$ \\
\hline CMBE-CLDRAD & Climate Modeling Best Estimate (CMBE) & $\begin{array}{l}\text { Best estimate of selected cloud and radiation relevant } \\
\text { quantities tailored to climate modelers for use in } \\
\text { evaluation of global climate models. }\end{array}$ \\
\hline MERGESONDE & Merged Sounding & $\begin{array}{l}\text { Combines sondes, MWR, SMET, and ECMWF } \\
\text { model output for I-min time series of profiles of the } \\
\text { atmospheric thermodynamic state. }\end{array}$ \\
\hline MICROBASE & Continuous Baseline Microphysical Retrieval & $\begin{array}{l}\text { Continuous profiles of cloud microphysics derived from } \\
\text { merged sonde profiles. }\end{array}$ \\
\hline MPLCMASK & Micropulse Lidar Cloud Mask & $\begin{array}{l}\text { Retrieves cloud boundaries and applies lidar-specific } \\
\text { corrections to the measured backscattered lidar. }\end{array}$ \\
\hline MWRRET & MWR Retrievals & $\begin{array}{l}\text { Best estimate refined values of liquid water path and } \\
\text { precipitable water vapor from MWR }\end{array}$ \\
\hline QCRAD & $\begin{array}{l}\text { Data Quality Assessment for ARM } \\
\text { Radiation Data }\end{array}$ & $\begin{array}{l}\text { Data quality assessment and enhancement of data } \\
\text { continuity for ARM radiation data for all ARM facilities. }\end{array}$ \\
\hline SONDEADJUST* & Sonde-Adjust & $\begin{array}{l}\text { Corrects documented biases in radiosonde humidity } \\
\text { measurements. }\end{array}$ \\
\hline SWFLUXANAL & Shortwave Flux Analysis & $\begin{array}{l}\text { Times series analysis of SW to produce continuous } \\
\text { clear-sky SW and fractional sky cover estimates. }\end{array}$ \\
\hline VARANAL* & $\begin{array}{l}\text { SCM-Forcing Data, Cloud Microphysical } \\
\text { Properties and Radiative Heating Profiles }\end{array}$ & $\begin{array}{l}\text { Includes both the large-scale forcing terms and the } \\
\text { evaluation fields, which can be used for driving the } \\
\text { single-column models (SCMs) and cloud-resolving } \\
\text { models (CRMs) and validating model simulations. }\end{array}$ \\
\hline VISST $* *$ & $\begin{array}{l}\text { Minnis Cloud Products Using VISST } \\
\text { Algorithm }\end{array}$ & $\begin{array}{l}\text { Satellite based retrievals of cloud and radiation } \\
\text { properties using the Visible Infrared Solar-Infrared Split } \\
\text { Window Technique from Minnis' group at NASA/Langley }\end{array}$ \\
\hline
\end{tabular}


Nauru sites has been quite valuable for validating and improving space-based remote sensing in the tropics from a wide range of satellite instruments. Tropical cirrus cloud detection was assessed with ARM data for algorithms using the $1.38-\mu \mathrm{m}$ reflectance channel from the Moderate-Resolution Imaging Spectroradiometer (MODIS; see Roskovensky and Liou 2003), multiple infrared wavelengths from the Atmospheric Infrared Sounder (AIRS; see Kahn et al. 2005), and from the Cloud-Aerosol Lidar and Infrared Pathfinder Satellite Observations (CALIPSO) lidar (Thorsen et al. 2011). Island data have been used to evaluate techniques defining cloud structure (i.e., cloud-top and cloud-base heights and width) from Multiangle Imaging Spectroradiometer (MISR; Kassianov et al. 2003) and geostationary satellite data (Hollars et al. 2004). Microphysical properties such as cloud optical depth and ice and liquid water path have been compared with the TWP ARM data using algorithms applied to measurements from the Advanced Microwave Sounding Unit (AMSU; Grody et al. 2006), AIRS (Yue and Liou 2009), MODIS (Roskovensky and Liou 2006), and dual instruments, MODIS and Advanced Microwave Scanning Radiometer for Earth

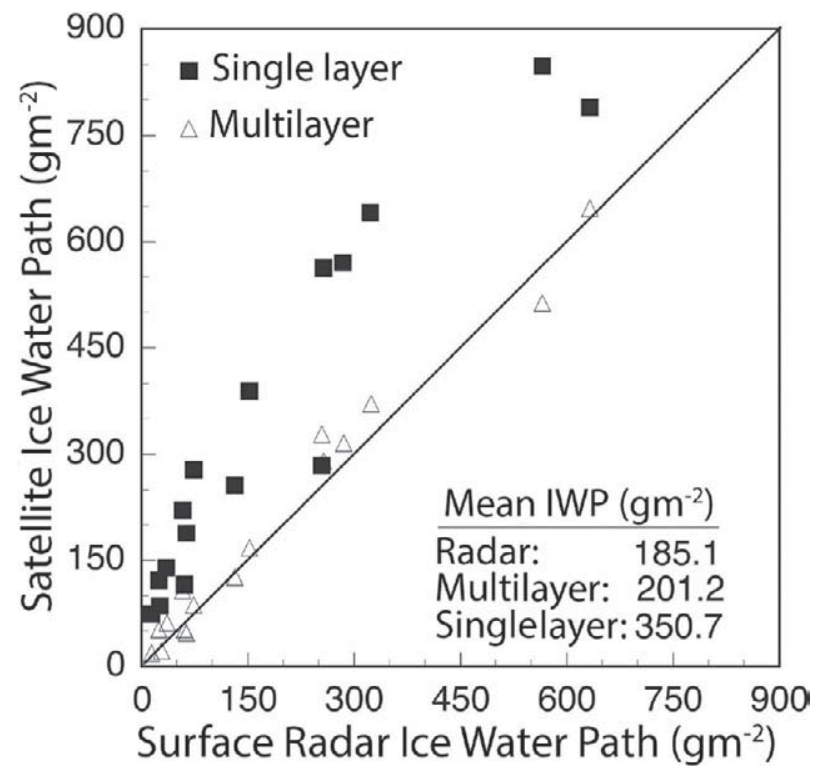

FIG. 8. Comparison of satellite-retrieved ice water path (IWP) retrievals from Aqua data with simultaneous IWP retrievals using the ground-based millimeter cloud radar (MMCR) reflectivity data for overcast multilayered cloud systems over the ARM TWP Manus site occurring during the daytime Aqua overpasses, Dec 2004-Feb 2005. The single and multilayer cloud retrievals used the Visible Infrared Solar-Infrared Split-Window Technique (VISST) and the Multi-layer Cloud Retrieval System (MCRS). Adapted from Huang et al. (2006).
Observing System (AMSR-E), on Aqua (Huang et al. 2006). For example, Huang et al. (2006) used cloud ice water path (IWP) derived from Manus MMCR data in ice-over-liquid multilayered cloud systems to assess a new multilayered cloud retrieval system (MCRS). As seen in Fig. 8, MCRS produces improved IWP estimates relative to the MMCR IWP compared to a frequently used single-layered Visible Infrared Solar-Infrared Split-Window Technique (VISST) satellite cloud retrieval method (Minnis et al. 2011).

In addition to cloud products, the ARM data have been used to make substantial contributions to other remote sensing problems. For instance, as part of the Aerosol Robotic Network (AERONET; Holben et al. 1998), the Nauru sun photometer aerosol optical depth measurements have been used extensively to validate satellite-based aerosol retrieval methods (e.g., Roskovensky and Liou 2006). Water vapor profiles and total column water have been used to verify the same parameters retrieved from AIRS (Yue et al. 2007; Bedka et al. 2010), AMSU (Grody et al. 2006), and Microwave Humidity Sounder (Moradi et al. 2010) data. The ARM island rawinsondes were crucial for confirming tropical sea surface temperature retrievals from Multispectral Thermal Imager data (Kurzeja et al. 2001) and winds derived from geostationary satellites (Velden and Bedka 2009). Continuous surface radiation measurements at Nauru and Manus aided the development of techniques for estimating surface longwave fluxes from satellite-measured longwave fluxes (Zhou and Cess 2001; Gupta et al. 2010). They have also been used for assessing satellite-based estimates of albedo (Yang et al. 2008) and surface longwave and shortwave fluxes (Kratz et al. 2010; Yang et al. 2008; Zhang et al. 2010). Because of their locations on small islands in the tropical western Pacific, the Manus and Nauru measurements continue to provide important information for understanding and improving satellite remote sensing of the Earth-atmosphere system.

Combining satellite data with the island measurements enhances our ability to study many atmospheric phenomena. Nordeen et al. (2001) used Nauru rawinsonde data and geostationary imagery to determine the effects of small islands on trade cumulus fields. Dong et al. (2008) matched satellite and surface flux data from Nauru, Manus, and other sites to compute the atmospheric absorption in the presence of deep convective clouds and found that the theoretical calculations were within the errors bounds of the observations. Jensen and Del Genio (2003) show that small ice particles in convective or stratiform rain and anvil regions above the tops detected by satellite 
precipitation radar have a significant effect on surface SW fluxes and that the flux is very sensitive to the assumed small particle size.

SUMMARY. The U.S. DOE ARM Program has compiled comprehensive measurements of clouds, radiation, and associated meteorological parameters in the TWP for more than 10 years. The datasets are a valuable resource to the worldwide research community. Our intent here is to highlight the significant contribution of the datasets to our knowledge of tropical cloud systems and tropical meteorology.

While we have presented a broad spectrum of the scientific contributions that rely on the decadelong record from the Nauru and Manus sites, these examples are not intended to be a comprehensive accounting. A simple search of the ARM Publications Database (www.arm.gov/publications/db) for the words "Manus," "Nauru," or "TWP" in the title or key words identifies 143 journal papers published between 1996 and 2012, along with an additional 250 conference proceedings and presentations. A visual scan of the titles finds research topics from large-scale tropical dynamics and variability to cloudscale processes and precipitation to microphysics and aerosol. While many of these topics were part of our original science vision for the TWP, the breadth of the research has substantially exceeded our expectations.

The new challenge at the TWP sites lies in expanding from the vertically pointing, or "soda straw," view that the ARM remote sensors have used since operations began in the TWP to sampling the local spatial variability in clouds and precipitation. Meeting this challenge requires enhancing measurement capabilities, which was enabled by funding from the American Recovery and Reinvestment Act, and developing new data processing and retrieval algorithms, an activity that continues now and into the future. Scanning precipitation and cloud radars will augment already upgraded versions of the vertically pointing cloud radars and lidars. This expanded spatial view integrated through time will facilitate a new generation of process-oriented data analysis and modeling studies of cloud field evolution.

One weakness of the TWP sites for model evaluation has been the lack of adequate dynamic and thermodynamic context with which to drive cloud-resolving and single-column modeling studies. However, the recent Tropical Warm PoolInternational Cloud Experiment (TWP-ICE; May et al. 2008) held in the Darwin area showed that the combination of precipitation amounts from scanning precipitation radar, centrally located soundings, and reanalysis products provides an adequate constraint to construct useful model forcing datasets (Xie et al. 2010). Forcing data can be further augmented by enhanced sounding periods. For example, the ARM MJO Investigation Experiment (AMIE; Long et al. 2010) conducted on Manus from October 2011 through March 2012 includes continuous $\left(8\right.$ day $\left.^{-1}\right)$ sondes. A 6-month forcing dataset will be constructed from these sondes in combination with data from the new Manus precipitation radar. This forcing dataset will provide a unique opportunity for ARM equatorial TWP model studies. While the existing decade-long record of clouds, radiation, and atmospheric state provides a unique observational record that will continue to be exploited by the research community, the next decade offers significant new opportunities for atmospheric research in this challenging region thanks to ongoing observations and the new improved instrumentation.

ACKNOWLEDGMENTS. The authors acknowledge the ongoing support of the Office of Biological and Environmental Research (OBER) of the U.S. Department of Energy (DOE) as part of the Atmospheric Radiation Measurement (ARM) and Atmospheric System Research (ASR) Programs. We are grateful to the program managers at DOE OBER who have been responsible for ARM and ASR from the inception of the program. Without their unwavering support, we would not have these sites or the associated science. Thanks to Dr. Julia Flaherty for her efforts contributing to Figs. 1 and 6. Special recognition is extended to the dedicated scientists, engineers, and technical staff who were responsible for the original site designs and installations, and to those who were and continue to be responsible for the operation and maintenance of the sites and instruments that produce the data used in this study. We cannot list you all here, but your diligent and dedicated efforts are deeply appreciated.

\section{REFERENCES}

Ackerman, T. P., and G. M. Stokes, 2003: The Atmospheric Radiation Measurement Program. Phys. Today, 56, 38-44, doi:10.1063/1.1554135.

_ - W. E. Clements, F. J. Barnes, and D. S. Renne, 1999: Tropical Western Pacific Cloud and Radiation Testbed: Science, siting, and implementation strategies. ARM Tech. Rep. ARM-99-004, 71 pp. [Available online at www.arm.gov/publications/site_reports /twp/arm-99-004.pdf.]

Bedka, S., R. Knuteson, H. Revercomb, D. Tobin, and D. Turner, 2010: An assessment of the absolute accuracy of the Atmospheric Infrared Sounder v5 
precipitable water vapor product at tropical, midlatitude, and arctic ground-truth sites: September 2002 through August 2008. J. Geophys. Res., 115, D17310, doi:10.1029/2009JD013139.

Boyle, J. S., and Coauthors, 2005: Diagnosis of Community Atmospheric Model 2 (CAM2) in numerical weather forecast configuration at Atmospheric Radiation Measurement sites. J. Geophys. Res., 110, D15S15, doi:10.1029/2004JD005042.

Bretherton, C. S., M. E. Peters, and L. E. Back, 2004: Relationships between water vapor path and precipitation over the tropical oceans. J. Climate, 17, 1517-1528.

Chen, Y., and A. D. Del Genio, 2009: Evaluation of tropical cloud regimes in observations and a general circulation model. Climate Dyn., 32, 355-369.

Clothiaux, E. E., T. P. Ackerman, G. G. Mace, K. P. Moran, R. T. Marchand, M. A. Miller, and B. E. Martner, 2000: Objective determination of cloud heights and radar reflectivities using a combination of active remote sensors at the ARM CART sites. J. Appl. Meteor., 39, 645-665.

Comstock, J. M., and C. Jakob, 2004: Evaluation of tropical cirrus cloud properties derived from ECMWF model output and ground based measurements over Nauru Island. Geophys. Res. Lett., 31, L10106, doi:10.1029/2004GL019539.

_ , T. P. Ackerman, and G. G. Mace, 2002: Groundbased lidar and radar remote sensing of tropical cirrus clouds at Nauru Island: Cloud statistics and radiative impacts. J. Geophys. Res., 107, 4714, doi:10.1029/2002JD002203.

Del Genio, A. D., Y. Chen, D. Kim, and M.-S. Yao, 2012: The MJO transition from shallow to deep convection in CloudSat/CALIPSO data and GISS GCM simulations. J. Climate, 25, 3755-3770.

Deng, M., and G. G. Mace, 2008: Cirrus cloud microphysical properties and air motion statistics using cloud radar Doppler moments: Water content, particle size, and sedimentation relationships. Geophys. Res. Lett., 35,L17808, doi:10.1029/2008GL035054.

Dinh, T., D. R. Durran, and T. Ackerman, 2012: Cirrus and water vapor transport in the tropical tropopause layer-Part 1: A specific case modeling study. Atmos. Chem. Phys. Discuss., 12, 9799-9815, doi:10.5194/ acp-12-9799-2012.

DOE, 1996: Science Plan for the Atmospheric Radiation Measurement Program (ARM). DOE Tech. Rep. DOE/ER-0670T, 86 pp. [Available online at www .arm.gov/publications/programdocs/doe-er-0670t. pdf.]

Dong, X., and Coauthors, 2008: Using observations of deep convective systems to constrain atmospheric column absorption of solar radiation in the optically thick limit. J. Geophys. Res., 113, D10206, doi:10.1029/2007JD009769.

Fueglistaler, S., and Q. Fu, 2006: Impact of clouds on radiative heating rates in the tropical lower stratosphere. J. Geophys. Res., 111, D23202, doi:10.1029/2006JD007273.

Grody, N., J. Zhao, R. Ferraro, F. Weng, and R. Boers, 2006: Determination of precipitable water and cloud liquid water over oceans from the NOAA-15 Advanced Microwave Sounding Unit. J. Geophys. Res., 106, 2493-2953.

Gupta, S. K., D. P. Kratz, P. W. Stackhouse, A. C. Wilber, T. Zhang, and V. E. Sothcott, 2010: Improvement of surface longwave flux algorithms used in CERES processing. J. Appl. Meteor. Climatol., 49, 1579-1589.

Hannah, W. M., and E. D. Maloney, 2011: The role of moisture-convection feedbacks in simulating the Madden-Julian oscillation. J. Climate, 24, 2754-2770.

Hartmann, D. L., L. A. Moy, and Q. Fu, 2001: Tropical convection and the energy balance at the top of the atmosphere. J. Climate, 14, 4495-4511.

Holben, B. N., and Coauthors, 1998: AERONET-A federated instrument network and data archive for aerosol characterization. Remote Sens. Environ., 66, $1-16$.

Hollars, S., Q. Fu, J. M. Comstock, and T. P. Ackerman, 2004: Comparisons of cloud-top height retrievals from ground-based 35-GHz MMCR and GMS-5 satellite observations at ARM TWP Manus site. Atmos. Res., 72, 169-186.

Holloway, C. E., and J. D. Neelin, 2009: Moisture vertical structure, column water vapor, and tropical deep convection. J. Atmos. Sci., 66, 1665-1683.

Huang, J., P. Minnis, B. Lin, Y. Yi, T.-F. Fan, S. Sun-Mack, and J. K. Ayers, 2006: Determination of ice water path in ice-over-water cloud systems using combined MODIS and AMSR-E measurements. Geophys. Res. Lett., 33, L21801, doi:10.1029/2006GL027038.

Hume, T., and C. Jakob, 2005: Ensemble single column modeling (ESCM) in the tropical western Pacific: Forcing data sets and uncertainty analysis. J. Geophys. Res., 110, D13109, doi:10.1029/2004JD005704.

_ , and _ 2007: Ensemble single column model validation in the tropical western Pacific. J. Geophys. Res., 112, D10206, doi:10.1029/2006JD008018.

Jakob, C., R. Pincus, C. Hannay, and K.-M. Xu, 2004: The use of cloud radar observations for model evaluation: A probabilistic approach. J. Geophys. Res., 109, D03202, doi:10.1029/2003JD003473.

—, G. Tselioudis, and T. Hume, 2005: The radiative, cloud and thermodynamic properties of the major 
tropical western Pacific cloud regimes. J. Climate, 18, 1203-1215.

Jensen, M. P., and A. D. Del Genio, 2003: Radiative and microphysical characteristics of deep convective systems in the tropical western Pacific. J. Appl. Meteor., 42, 1234-1254.

- , and - 2006: Factors limiting convective cloud-top height at the ARM Nauru Island Climate Research Facility. J. Climate, 19, 2105-2117.

Kahn, B. H., and Coauthors, 2005: Nighttime cirrus detection using Atmospheric Infrared Sounder window channels and total column water vapor. J. Geophys. Res., 110, D07203, doi:10.1029/2004JD005430.

Kassianov, E., T. Ackerman, R. Marchand, and M. Ovtchinnikov, 2003: Satellite multiangle cumulus geometry retrieval: Case study. J. Geophys. Res., 108, 4117, doi:10.1029/2002JD002350.

Kim, D., and Coauthors, 2009: Application of MJO diagnostics to climate models. J. Climate, 22, 64136436.

Kollias, P., and B. A. Albrecht, 2010: Vertical velocity statistics in fair-weather cumuli at the ARM TWP Nauru climate research facility. J. Climate, 23, 65906604.

Kratz, D. P., S. K. Gupta, A. C. Wilber, and V. E. Sothcott, 2010: Validation of the CERES edition 2B surfaceonly flux algorithms. J. Appl. Meteor. Climatol., 49, 164-180.

Kurzeja, R. J., E. Villa-Aleman, and A. J. Garrett, 2001: Comparison of MTI satellite-derived surface water temperatures and in situ measurements. Tech. Rep. WSRC-MS-2001-00576. [Available online at http:// sti.srs.gov/fulltext/ms2001576/ms2001576.html.]

Long, C. N., 1996: Surface radiative energy budget and cloud forcing: Results from TOGA COARE and techniques for identifying and calculating clear sky irradiance. Ph.D. dissertation, The Pennsylvania State University, 193 pp.

— , and T. P. Ackerman, 2000: Identification of clear skies from broadband pyranometer measurements and calculation of downwelling shortwave cloud effects. J. Geophys. Res., 105 (D12), 15609-15626.

— , and D. D. Turner, 2008: A method for continuous estimation of clear-sky downwelling longwave radiative flux developed using ARM surface measurements. J. Geophys. Res., 113, D18206, doi:10.1029/2008JD009936.

_ , T. P. Ackerman, K. L. Gaustad, and J. N. S. Cole, 2006: Estimation of fractional sky cover from broadband shortwave radiometer measurements. J. Geophys. Res., 111, D11204, doi:10.1029/2005JD006475.

— gation Experiment): Observations of the MaddenJulian oscillation for Modeling Studies Science Plan.
DOE/ARM Tech. Rep. DOE/SC-ARM-10-007, 25 pp. [Available online at www.arm.gov/publications /programdocs/doe-sc-arm-10-007.pdf.]

Mace, G. G., M. Deng, B. Soden, and E. Zipser, 2006: Association of tropical cirrus in the $10-15-\mathrm{km}$ layer with deep convective sources: An observational study combining millimeter radar data and satellitederived trajectories. J. Atmos. Sci., 63, 480-503.

Madden, R. A., and P. R. Julian, 1994: Observations of the 40-50 day tropical oscillation-A review. Mon. Wea. Rev., 122, 814-837.

Mather, J. H., 2005: Seasonal variability in clouds and radiation at the Manus ARM site. J. Climate, 18, 2417-2428.

—, T. P. Ackerman, W. E. Clements, F. J. Barnes, M. D. Ivey, L. D. Hatfield, and R. M. Reynolds, 1998: An atmospheric radiation and cloud station in the tropical western Pacific. Bull. Amer. Meteor. Soc., 79, 627-642.

_ S. A. McFarlane, M. A. Miller, and K. L. Johnson, 2007: Cloud products and associated heating rates in the tropical western Pacific. J. Geophys. Res., 112, D05201, doi:10.1029/2006JD007555.

May, P. T., J. H. Mather, G. Vaughan, C. Jakob, G. M. McFarquhar, K. N. Bower, and G. G. Mace, 2008: The Tropical Warm Pool International Cloud Experiment. Bull. Amer. Meteor. Soc., 89, 629-645.

McFarlane, S. A., and K. F. Evans, 2004: Clouds and shortwave fluxes at Nauru. Part II: Shortwave flux closure. J. Atmos. Sci., 61, 2602-2615.

— _ _ a and A. S. Ackerman, 2002: A Bayesian algorithm for the retrieval of liquid water cloud properties from microwave radiometer and millimeter radar data. J. Geophys. Res., 107, 4317, doi:10.1029/2001JD001011.

_ , J. H. Mather, and T. P. Ackerman, 2007: Analysis of tropical radiative heating profiles: A comparison of models and observations. J. Geophys. Res., 112, D14218, doi:10.1029/2006JD008290.

Minnis, P., and Coauthors, 2011: CERES Edition-2 cloud property retrievals using TRMM VIRS and Terra and Aqua MODIS data-Part I: Algorithms. IEEE Trans. Geosci. Remote Sens., 49, 4374-4400.

Moradi, I., S. A. Buehler, V. O. John, and S. Eliasson, 2010: Comparing upper tropospheric humidity data from microwave satellite instruments and tropical radiosondes. J. Geophys. Res., 115, D24310, doi:10.1029/2010JD013962.

Neale, R., and J. Slingo, 2003: The Maritime Continent and its role in the global climate: A GCM study. J. Climate, 16, 834-848.

Nordeen, M. L., P. Minnis, D. R. Doelling, D. Pethick, and L. Nguyen, 2001: Satellite observations of cloud 
plumes generated by Nauru. Geophys. Res. Lett., 28, 631-634.

Ovtchinnikov, M., T. Ackerman, R. Marchand, and M. Khairoutdinov, 2006: Evaluation of the multiscale modeling framework using data from the Atmospheric Radiation Measurement Program. J. Climate, 19, 1716-1729.

Romps, D. M., and Z. Kuang, 2011: A transilient matrix for moist convection. J. Atmos. Sci., 68, 2009-2025.

Roskovensky, J. K., and K. N. Liou, 2003: Detection of thin cirrus using a combination of $1.38-\mu \mathrm{m}$ reflectance and window brightness temperature difference. $J$. Geophys. Res., 108, 4570, doi:10.1029/2002JD003346.

— aerosol and thin cirrus optical depths over oceans from MODIS data: Some case studies. J. Atmos. Sci., 63, 2307-2323.

Stokes, G. M., and S. E. Schwartz, 1994: The Atmospheric Radiation Measurement (ARM) program: Programmatic background and design of the cloud and radiation test bed. Bull. Amer. Meteor. Soc., 75, 1201-1221.

Thayer-Calder, K., and D. A. Randall, 2009: The role of convective moistening in the Madden-Julian oscillation. J. Atmos. Sci., 66, 3297-3312.
Thorsen, T. J., Q. Fu, and J. Comstock, 2011: Comparison of the CALIPSO satellite and groundbased observations of cirrus clouds at the ARM TWP sites. J. Geophys. Res., 116, D21203, doi:10.1029/2011JD015970.

Velden, C. S., and K. M. Bedka, 2009: Identifying the uncertainty in determining satellite-derived atmospheric motion vector height attribution. J. Appl. Meteor. Climatol., 48, 450-463.

Wang, Y., C. N. Long, J. H. Mather, and X. D. Liu, 2011: Convective signals from surface measurements at ARM tropical western Pacific site: Manus. Climate Dyn., 36, 431-449, doi:10.1007/s00382009-0736-z.

Xie, S., T. Hume, C. Jakob, S. Klein, R. McCoy, and M. Zhang, 2010: Observed large-scale structures and diabatic heating and drying profiles during TWPICE. J. Climate, 23, 57-79.

Yang, F., K. Mitchell, Y.-T. Hou, Y. Dai, X. Zeng, Z. Wang, and X.-Z. Liang, 2008: Dependence of land surface albedo on solar zenith angle: Observations and model parameterization. J. Appl. Meteor. Climatol., 47, 2963-2982.

Yue, Q., and K. N. Liou, 2009: Cirrus cloud optical and microphysical properties determined from AIRS infrared spectra. Geophys. Res. Lett., 36, L05810, doi:10.1029/2008GL036502.

— - - S. C. Ou, B. H. Kahn, P. Yang, and G. G. Mace, 2007: Interpretation of AIRS data in thin cirrus atmospheres based on a fast radiative transfer model. J. Atmos. Sci., 64, 3827-3842.

Zhang, C., 2005: Madden-Julian oscillation. Rev. Geophys., 43, RG2003, doi:10.1029/2004RG000158.

Zhang, Y., C. N. Long, W. B. Rossow, and E. G. Dutton, 2010: Exploiting diurnal variations to evaluate the ISCCP-FD flux calculations and radiative flux analysis processed surface observations from BSRN, ARM, and SURFRAD. J. Geophys. Res., 115, D15105, doi:10.1029/2009JD012743.

Zhou, Y., and R. Cess, 2001: Algorithm development strategies for retrieving the downwelling longwave flux at the Earth's surface. J. Geophys. Res., 106, 12 477-12 488 .

Zhu, H., H. Hendon, and C. Jakob, 2009: Convection in a parameterized and superparameterized model and its role in the representation of the MJO. J. Atmos. Sci., 66, 2796-2811.

Zhu, P., and C. S. Bretherton, 2004: A simulation study of shallow moist convection and its impact on the atmospheric boundary layer. Mon. Wea. Rev., 132, 2391-2409. 